\title{
Therapeutic Uses of Spiral Enteroscopy
}

\author{
Marco Balzarini, Marco Orsello and Mario Del Piano \\ SCDO di Gastroenterologia, Azienda Ospedaliero, \\ Universitaria Maggiore della Carità, Novara \\ Italy
}

\section{Introduction}

Not long ago, the small intestine was an unexplored frontier in gastrointestinal endoscopy. New developments in enteroscopes have opened up this region of the gastro-intestinal tract but it remains a difficult organ to access. Until recently, it was not possible to access most of the small bowel using endoscopic techniques without concomitant surgery.

Capsule endoscopy and balloon-assisted enteroscopy thus represent decisive breakthroughs in this field. Small bowel enteroscopy was considered a technically challenging procedure often requiring much time. In the past diagnostic and therapeutic options for small bowel conditions have traditionally been limited and frustrating for endoscopists.

With the development of balloon-assisted enteroscopy and most recently, spiral enteroscopy, endoscopic diagnosis and treatment of the entire small intestine are now feasible without operative intervention.

As indications expand and caseloads grow, it is important for gastroenterologists to know how these procedures are done and to be familiar with their potential complications.

\section{Indication for deep enteroscopy}

The indications for enteroscopy of the small intestine are rising so small bowel endoscopy is enjoying a significant renaissance.

Deep enteroscopy offers the potential advantages of biopsy, treatment of bleeding lesions, and other therapeutic maneuvers including stricture dilation, and stent placement.

Lesions located within the proximal two thirds of the small bowel transit time on capsule endoscopy are thought to be amenable to deep enteroscopy performed via the anterograde approach. Table 1 summarizes reported indications, relating to spiral enteroscopy 1234567 .

The majority of the outcomes literature on deep enteroscopy pertains to double ballon enteroscopy (DBE), because publications on single ballon enteroscopy and spiral enteroscopy remain limited. A summary of the published DBE literature has demonstrated similar diagnostic yields to capsule endoscopy. In a summary of 16 published studies to date, the overall mean diagnostic yield was $67 \%$ with a treatment success rate of $64 \% .^{8}$. Double balloon enteroscopy has been reported to be diagnostic in a small percentage of patients with normal capsule examinations, particularly in the situation of ongoing acute obscure hemorrhage ${ }^{9}$ 
- Abnormal capsule endoscopy

- Abnormal radiologic imaging

- Anastamotic stricture

- Celiac disease

- Chronic abdominal pain

- Chronic diarrhea

- Fistula plug placement for enterocutaneous fistula

- Push enteroscopy (PE)

- Hepatojejunostomy stricture

- History of intestinal polyps (familial adenomatous polyposis, Gardner's syndrome)

- Iron deficiency anemia

- Obscure-occult gastrointestinal bleeding

- Obscure-overt gastrointestinal bleeding

- Small bowel fistula

- Small bowel obstruction

- Suspected small bowel Crohn's disease

- Therapeutic ERCP after Roux-en-Y gastric bypass

Table 1. Indication for spiral enteroscopy

Approximately $5 \%$ of patients presenting with acute or chronic gastrointestinal (GI) hemorrhage will have a responsible source located in the small intestine ${ }^{10}$. For patients residing in the United States or Europe, lesions most responsible for small bowel hemorrhage include arteriovenous malformations in 30\%-40\%11, ulcerations, other vascular disorders including Dieulafoy lesions, and small bowel neoplasms in 1\%-3\% of patients. ${ }^{12}$. Small bowel follow-through radiographs have demonstrated a low yield $(3 \%-20 \%)$ for pathologic findings in patients with obscure bleeding, and the findings are dependent upon the skill and time allotted by the radiologist for fluoroscopy ${ }^{13}$.

Other indications for deep enteroscopy other gastrointestinal hemmorhage are similar to capsule endoscopy and include evaluation of patients with polyposis syndromes, refractory celiac sprue, and other ulcerative small bowel disorders. Similar to capsule endoscopy, the yield of DBE in patients with chronic abdominal pain is very low

\section{Evolution of enteroscopy}

Intraoperative enteroscopy was initially performed in the 1950s with a rigid sigmoidoscope passed through an operative laparotomy. By the 1970s fiberoptic endoscopes were used for intraoperative enteroscopy ..$^{14}$ Intraoperative enteroscopy has a high diagnostic yield but has largely been replaced because of its high complication rate, need for a surgeon as well as an endoscopist, and postprocedural hospital stay.

Sonde enteroscopy was introduced in 1986 as an alternative to intraoperative enteroscopy, but it was eventually abandoned because it was labor intensive for the endoscopist and uncomfortable for the patient. 
Push enteroscopy was the most widely used endoscopic procedure, but only about 60 to 120 $\mathrm{cm}$ of small bowel can be visualized ${ }^{15}$. Further advancement is generally limited by intragastric or small-bowel looping. Advanced skill or training is not typically required to perform this procedure. The procedure is performed under conscious sedation and takes between 15 and 45 minutes. The overall complication rate from PE is approximately $1 \% 16$. Care must be taken to avoid trauma to the thin-walled duodenum and jejunum during advancement of the relatively stiff enteroscope.

Device-assisted enteroscopy techniques, including double balloon endoscopy (DBE), singleballoonenteroscopy (SBE), and spiral enteroscopy (SE), have both diagnostic and therapeutic capabilities. Double-balloon enteroscopy (DBE) emerged as an option for small bowel imaging in the United States in 2004; single-balloon enteroscopy (SBE) and spiral enteroscopy were introduced into the US market in 2007

\section{Device assisted enteroscopy}

Device-assisted enteroscopy is the modality of choice for evaluating disorders of the midgut whenever tissue acquisition or therapeutic intent is cogent. This new term, mid-gut, refers to the small bowel between the ampulla and the ileocecal valve. ${ }^{17}$.

Although capsule endoscopy can visualize the entire small intestine, a main disadvantage is the inability to obtain biopsy specimens, navigate altered anatomy, or perform therapeutic maneuvers via this procedure.

\subsection{Ballon assisted enteroscopy}

New techniques such as DBE and SBE use techniques designed to pleat the small bowel on the endoscope and overtube. They work on the principle of push-pull advancement through the small bowel by alternately inflating and deflating the balloons on the overtube and the enteroscope (in DBE) 18

\subsubsection{Double ballon enteroscopy}

The concept of DBE was introduced in 199719 and was subsequently introduced into the United States in 2004 (Fujinon Inc, Saitama, Japan). The development of DBE was based on the concept that "stretching" of the small intestinal wall prevents further endoscopic advancement, and that the usage of a balloon would grip the intestinal wall and prevent subsequent loop formation ${ }^{20}$.

The diagnostic enteroscope (EN450P5) has a 200-cm working length, an endoscope diameter of $8.5 \mathrm{~mm}$, and an accessory channel of $2.2 \mathrm{~mm}$. The therapeutic enteroscope (EN450T5) has a diameter of $9.4 \mathrm{~mm}$ and an accessory channel of $2.8 \mathrm{~mm}$.

\subsubsection{Single ballon enteroscopy}

The SBE system (Olympus Corporation, Tokyo, Japan) was developed in 2006 and introduced subsequently into the commercial market in 2007.21

The rationale behind development of the SBE system was to reduce the learning curve for balloon-assisted enteroscopy, avoid the difficulty of attaching the enteroscope balloon to the distal tip of the scope encountered in DBE, and eliminate the requirement of inflating and deflating 2 balloons in multiple steps with the current DBE insertion technique. 


\subsection{Spiral enteroscopy}

In addition to balloon assisted enteroscopy using double or single balloons, the novel technique of spiral enteroscopy (SE) has recently been reported.

This technique uses a flexible over-tube threaded with a pliable plastic spiral to grip the small bowel (Figure 1)

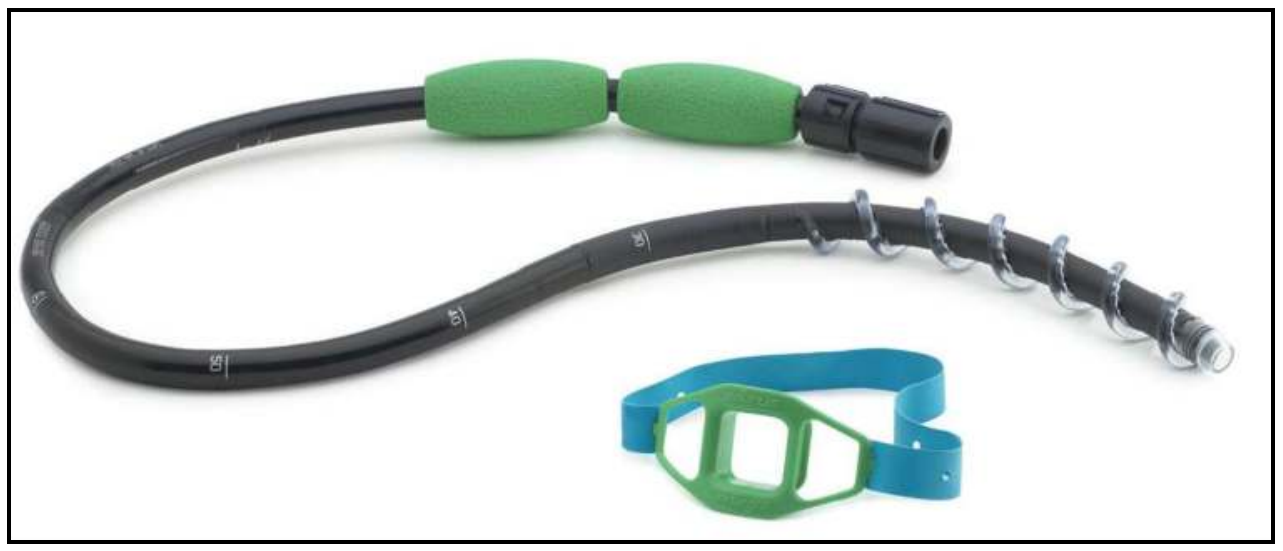

Fig. 1. Spiral overtube

Although the earlier prototypes were placed over a pediatric colonoscope, the newer devices are used with enteroscopes.

Rotational torque applied by the operator is converted into plication of the small bowel over the over-tube as the enteroscope advances.

Anterograde enteroscopic introduction with the spirus overtube helps to advance compatible enteroscopes beyond to Ligament of Treitz, the fixed portion of small bowel within the abdominal cavity. Rotation of the overtube beyond the Ligament of Treitz, allows a spiral to pleat the segment of the small bowel where disease is most commonly found (Figure 2).

The first case utilizing rotate to advance was performed in 2006 by Drs. Akerman and Cantero 22 .

Spiral enteroscopy can also be performed in post-gastric surgery patients, and can be used in Roux-en-Y patients requiring endoscopic retrograde cholangiopancreatography.

The Endo-Ease Discovery SB system is an overtube with an outer spiral, which was cleared for enteroscopy by the FDA in 2008. The device is $118 \mathrm{~cm}$ long with a hollow spiral $5.5 \mathrm{~mm}$ high and $22 \mathrm{~cm}$ long with a locking device on the proximal end. The Discovery SB has an outer diameter of $16 \mathrm{~mm}$ and an internal diameter of $9.8 \mathrm{~mm}$. The tube lightly connects to the existing enteroscopes by a "gentle lock" and rotates independently from the enteroscope. The lock can be disengaged and reengaged, allowing the option of advancing the enteroscope through the overtube when unlocked or performing spiral enteroscopy with the spiral overtube when locked. 


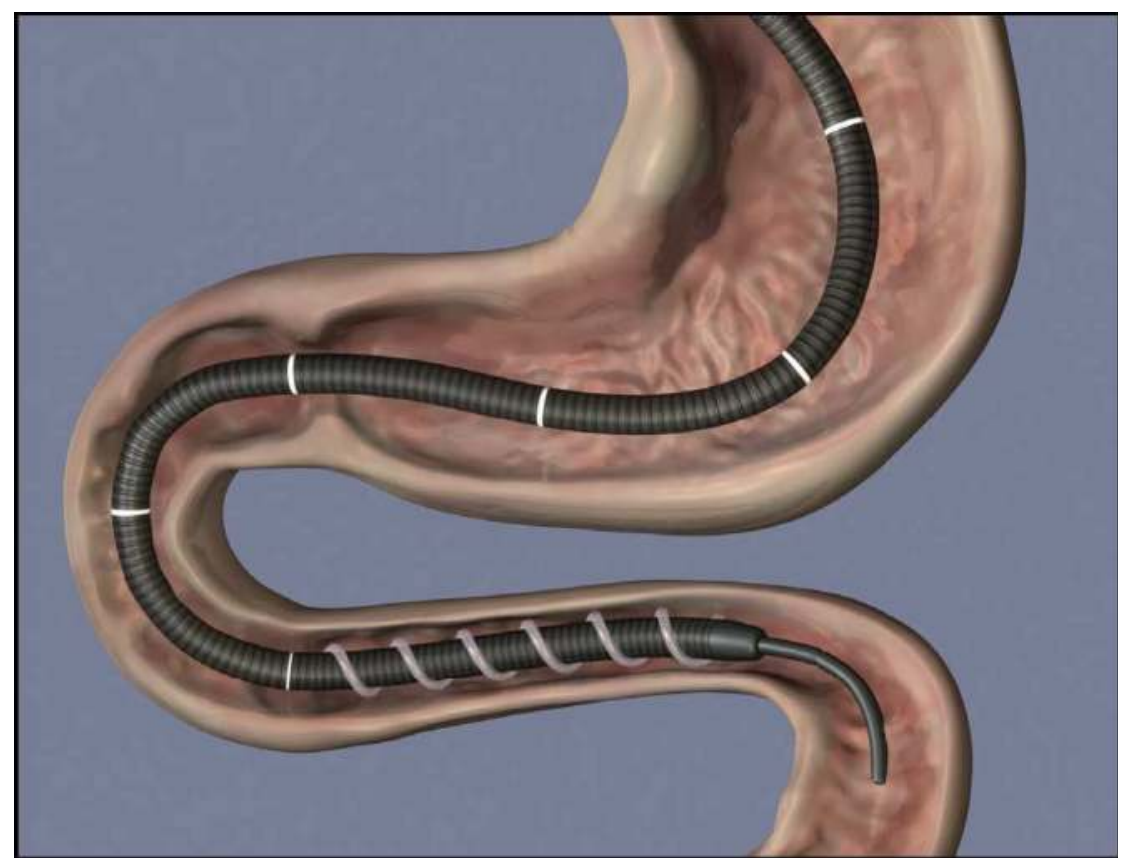

Fig. 2. Concept of "rotate to advance."

The Spirus overtube can be paired with existing enteroscopes measuring up to $9.4 \mathrm{~mm}$. The product is a single use device sterilized.

An in vitro porcine model was created to demonstrate spiral advancement and pleating tecniques.

Spiral enteroscopy is possible also with retrograde approach. For this use exists a dedicated spiral tip overtube (Vista overtube, tube length $100 \mathrm{~cm}$, tube outer diameter $1.85 \mathrm{~cm}$, outer diameter includes spirals $3.33 \mathrm{~cm}$ ). This overtube can be preloaded onto pediatric colonoscope or enteroscope. Initaial experience with this device are reported.23

While all three of these methods allow intubation of the deep small bowel, these techniques provide unique challenges involving patient sedation. Preliminary reports detailing the use of spiral enteroscopy have used anesthesiologist-guided monitored anesthesia care exclusively for sedation. ${ }^{24}$ When standard sedation is used, spiral enteroscopy is technically feasible, clinically useful, and safe. Deep small bowel enteroscopy using the spiral overtube can be successfully and safely accomplished with gastroenterologist- guided, nurseadministered standard sedation also in a patient population with multiple comorbidities and a high prevalence of diagnostic findings requiring endoscopic therapy.

Although some of them only published in abstract form, some studies have compared SE with DBE and shown that SE required significantly shorter time than DBE to insert to similar depths 25 26. Initial studies of deep enteroscopy focused on presenting narrative experiences with the individual techniques. Comparative trials have been conducted to compare the utility of these various techniques in terms of their diagnostic yield, deep of maximal insertion allowed, efficacy, and complications 27 
In one prospective study on 35 patients DBE showed a clinically higher diagnostic yield than spiral enteroscopy but there was non difference in investigation performance, as assessed by time o insertion, duration of enteroscopy and amount of sedoanalgesia required. ${ }^{28}$

Khashab et al. ${ }^{29}$ reported the first study comparing SE and SBE. Although SE yielded greater depth of maximal insertion than SBE, both techniques had similar diagnostic yields and procedure times. In addition, both techniques were safe and were particularly useful in evaluation and treatment of patients with obscure gasto-intestinal bleeding.

As seen above, the strengths of SE are rapid advancement in the small bowel and better control of the endoscope, which makes it easy to conduct endoscopic interventions.

\subsubsection{Complcations}

Serious complications of deep small bowel enteroscopy occur infrequently. In published series, severe complications occur in deep small bowel enteroscopy in 0.3 to $4 \%$ of cases.

There are 2950 patients who have undergone spiral enteroscopy from August 2006 until May 2009. Cases have been performed in North America and Europe. Severe complications were defined as pancreatitis, nontransient intussusception, bleeding requiring transfusion or admission to the hospital, cardio-pulmonary arrest during a procedure and perforation. There were no reported complications of esophageal or gastric perforations, severe bleeding requiring transfusion, or cardio-pulmonary arrest during or resulting from the spiral enteroscopy procedures. There were 9 reported severe complications $(0.3 \%)$ and no deaths reported as a result of the procedure. There were eight small bowel perforations $(0.27 \%)$, all were recognized immediately. Four small bowel perforations occurred in the jejunum. Three duodenal perforations occurred while pushing to advance the scope through the duodenum. Two of four jejunal perforations occurred during therapeutic interventions. One perforation occurred in a Roux en $\mathrm{Y}$ patient. None of the perforations appeared to occur during rotation of the overtube to pleat the small bowel. Five perforations occurred when the experience of the physician was less than 10 cases.

Perforations may be minimized by advancing the enteroscope only when the lumen is clearly visualized and maintaining the scope tip $25-30 \mathrm{~cm}$ from the end of the Discovery SB overtube.

Also in a typical US patient population with multiple comorbidities and high prevalence of pathologic finding spiral enteroscopy is a technically feasible and safe way to perform diagnostic and therapeutic deep small bowel enteroscopy and in conclusion Spiral enteroscopy is a safe procedure with a low rate serious complications.

\subsubsection{Procedure}

Spiral enteroscopy applies the mechanical advantage of a screw to convert rotational force into linear force and pleat the small bowel on the enteroscope.

The patients is placed in the left lateral decubitus position for the procedure and received monitored anesthesia with propofol/midazolam hydrochloride/fentanyl or general anesthesia, according to the anesthesiologist's preference. Before performing the procedure, a proprietary lubricant is applied thoroughly to the overtube channel and than the DSB device is placed over the enteroscope. The distal end of the DSB is positioned $25 \mathrm{~cm}$ from the tip of the enteroscope and locked into place with the DSB proximal collar. When locked tightly onto the coupler at the proximal end of the overtube at the $140 \mathrm{~cm}$ mark, the scope is 
inserted into the esophagus. All subsequent movements of the scope must be done with gentle rotation of the overtube except when the overtube coupler has been unlocked. Engagement of the spiral in the duodenum may be difficult and it requires backing up of the scope and the overtube.

To rotate the tube, the hands are placed on the 2 soft handles located just below the lock. A special curved mouthpiece with a bigger aperture to accommodate the DSB and the enteroscope is used. Once past the ligament of Treitz the mobile small bowel can be plated on the overtube using spiral technique (Figure 3).

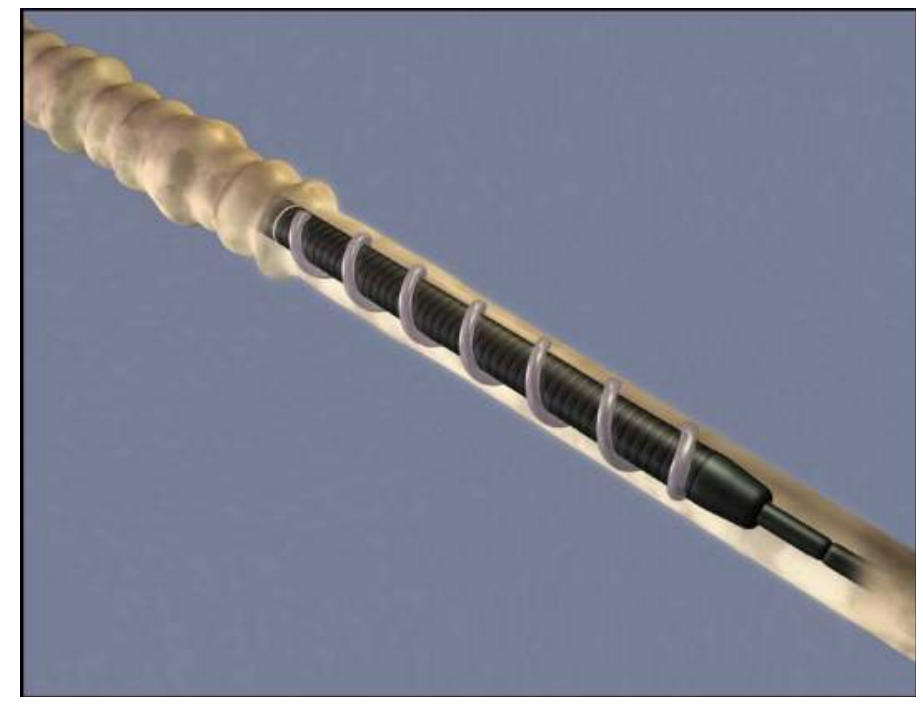

Fig. 3. Rotation pleats the small bowel.

Two operators are required, one for spiralling and a second for steering and insufflation to maximize insertion. Minimal insufflation is used. Spiral advancement is continued as long as the overtube rotates easily and the small bowel continues to be pleated onto the overtube. When advancement slow or rotations become difficult the overtube may be straightened and pulled back to remove loops. This achives a stray scope that is optimal for spiral advancement. When working optimally the spiral advancement has a rapid one to one advancement whith a minimal slippage of the overtube.

Fluoroscopic guidance can be helpful but not necessary to assist in advancing through the small bowel.

The overtube let maneuver the enteroscope if needed while it remains in place indeed the endoscope can be withdrawn completely from the overtube and reinserted without loss of position.

Withdrawal of the overtube and endoscope is accomplished by counter clockwise rotation of the overtube. The counter clockwise rotation unpleats the small bowel from the overtube By rotation of the DSB, advancement can be continued until the pleating of small bowel with rotation is no longer effective. The enteroscope is then unlocked from the DSB and pushed through the overtube for added depth of small bowel intubation. The DSB is then gradually withdrawn by anticlockwise rotation of the DSB, and the small-bowel mucosa examined. 
Small-bowel pleating is accomplished without apparent twisting of the small bowel because the mesentery attachment to the small bowel resists the rotation of the small bowel.

In a setting when prompt endoscope extubation may have become necessary, rapid anticlockwise rotation would have achieved rapid withdrawal of the DSB.

The DSB has many features that make it a safe and easy device to use.

The shaft is uniformly more flexible at the distal end and transitions gradually to a less flexible proximal end, resulting in optimal integration of torque transmission and flexibility. The locking device on the DSB allows spiral enteroscopy and standard push enteroscopy techniques to be used in conjunction to advance the enteroscope through the small bowel. During withdrawal of the enteroscope, the DSB is rotated anticlockwise, which results in the pleated small bowel gradually coming off the device, allowing for controlled, careful examination of the small-bowel mucosa.

Spiral enteroscopy also has potential advantages over DBE and SBE, including speed of advancement through the small bowel, excellent controlled withdrawal especially useful for therapeutic maneuvers, and ability to completely withdraw the enteroscope and maintain position in the small bowel.

SE allows similar insertion depths to be reached as with DBE but the positioning with SE for collecting samples and for therapy is more stable than with DBE.

When using retrograde approach the endoscope is introduced in the usual fashion through the anus and advanced to where the colon lumen straightened out, usually in the descending or transverse colon. The overtube is disengaged and advanced over the endoscope using clockwise rotation; thus, the colonoscope served as a "guidewire" for the overtube. Since this maneuver usually resulted in simultaneous advancement of the tip of the colonoscope, it is important to always maintain good visibility of the lumen. When visualization of the lumen is not possible, overtube insertion is stopped, and water irrigation is performed to expose the lumen. Insufflation is kept to a minimum, and carbon dioxide can be used. If this failed, the scope can be gently pulled back while holding the overtube, and rarely spinning the overtube counter-clockwise, until the lumen is seen. The tip of the endoscope is usually advanced to the transverse colon or distal ascending colon in this fashion, where maximal overtube insertion usually occurred. The cecum is reached by disengaging the overtube and, while holding the handle at the anus, pushing the endoscope through the overtube. Once the ileum is intubated, the endoscope is exclusively advanced by pushing.

Table 2 shows a list of reported diagnostic/therapeutic interventions with spiral enteroscopy. In particular management of patients with small-bowel obstruction distal to the third part of the duodenum can be challenging. These patients are often poor surgical candidates, and placement of a self-expanding metal stent can be technically demanding. Deploying a stent distal to an endoscope is technically challenging, requiring a stable position to effectively traverse the stricture and deploy a self-expanding metal stent. The configuration of the spirals of the overtube is such that the bowel is held in a very secure position, providing stability at the distal tip, which greatly assists self-expanding metal stent placement and other interventions ${ }^{30}$. The accessory channel of commercially available enteroscopes is not large enough to admit an enteral stent. This problem is overcome by using the DSB overtube as a vehicle for deploying SEMS and conceivably other therapies. However, this is a relatively new technique, and, as such, larger numbers of cases and further experience are required to determine whether there are any significant side effects. 
- Biliary:

- Balloon sphincteroplasty and sludge extraction

- Cannulation/sphincterotomy

- Pancreatic stent placement

- Stent removal with stricture dilation

- $\quad$ Stone extraction and biliary stent placement

- Lumenal:

- Argon plasma coagulation

- Biopsy

- Bipolar cauterization

- Enteral stent placement (for malignant obstruction)

- $\quad$ Fistula plug placement

- Foreign body retrieval (percutaneous endoscopic gastrostomy tube bumper)

- India ink tattoo

- Polypectomy

Table 2. Diagnostic/therapeutic interventions with spiral enteroscopy

\subsubsection{Spiral enteroscopy in surgiclly altered gastrointestinal anatomy}

Surgically altered gastrointestinal anatomy presents considerable impediments for accessing the pancreaticobiliary tree. Endoscopic methods for accessing the biliary and pancreatic ducts in patients with surgically altered anatomy can be difficult and patients with surgically altered upper gastro-intestestinal tract anatomy pose a challenge to endoscopic biliary interventions.

Endoscopic treatments are preferable because they are less invasive than either transhepatic or surgical options.

Performance of ERCP's in cases of Roux-en-Y anastamosis has presented particular challenges with success rates at reaching the biliary and pancreatic orifices using standard endoscopic techniques up to a maximum of $50 \%$. One of the most common causes of difficulty is the inability of the endoscope to reach the papilla of Vater or the bilio-enteric anastomosis, due to the length of the passage or the angle of the anastomosis.

Cholelithiasis occurs in up to $38 \%$ of gastric bypass patients within 6 months of surgery. Cholecystectomy is not routinely performed in asymptomatic individuals with gallstones, leaving choledocolithiasis as a potential complication following gastric bypass.

Because of the length of the Roux limb and the acute angle of the jejunal-jejunal anastomis, ERCP is especially challenging and may not be feasible with standard equipment.

Wire guided passage of a duodenoscope has a demonstrated cannulation success rate of only $67 \%$. Invasive techniques such as percutaneous gastrostomy tube placement and transhepatic access may carry additional risk and comorbidity.

Recently, balloon enteroscopy (BE) techniques such as double-balloon enteroscopy (DBE) or single-balloon enteroscopy (SBE) have made it easier to perform ERCP in these patients ${ }^{31}$ Although data on the use of SE are limited, the usefulness of SE for ERCP in patients with surgically altered anatomy is expected to be equal to or more than that of balloon enteroscopy. 
Although only published in abstract form, some studies on SE-assisted ERCP have been reported.

Chandrasekharaet al. ${ }^{32}$ reported a series of 5 patients undergoing ERCP with SE. Three patients had Roux-en-Y gastric bypass and 2 were status post-pancreaticoduodenectomy. All procedures were performed using the Olympus SIF-Q 180 enteroscope and DSB, and the success rate was $80 \%$.

Shah $^{33}$ reported a series of 13 patients undergoing SE-assisted ERCP. Post-surgical anatomy included Roux-en-Y gastric bypass $(n=6)$, liver transplant $(n=6)$, and hepaticojejunostomy post liver resection $(n=1)$. Access to the papilla or anastomosis was achieved in $11 / 13$ patients $(85 \%)$ and ERCP was successfully performed in 9/13 (62\%). Complications were seen in 2 patients, including mild pancreatitis and self-limiting hypopharyngeal trauma.

Sanjay et al. ${ }^{34}$ reported that SE-assisted ERCP was performed in 3 patients including 2 patients for whom DBE-assisted ERCP had failed once. Successful selective cannulation and therapeutic intervention were achieved in all 3 cases. Mean total procedure time was $117 \mathrm{~min}$.

In conclusion Spiral enteroscopy ERCP is a new technique that is a highly effective platform for reaching the pancreaticobiliary orifice in Roux-en-Y patients. Spiral enteroscopy ERCP also provides excellent stability for high success rates for completion of ERCP's.

Spirus enteroscopy reaches the biliary-enteric anastomosis or papilla in most patients with altered surgical anatomy and is associated with technical success in the majority of patients in whom access to the afferent limb is achieved. Modification of enteroscope-length ERCP accessories may improve success.

\section{Clinical case}

Our patient is a 26 yrs old woman, with Peutz-Jeghers syndrome and history of multiple abdominal surgeries: ileal resection for occlusion and for polyps removal in distal ileum.

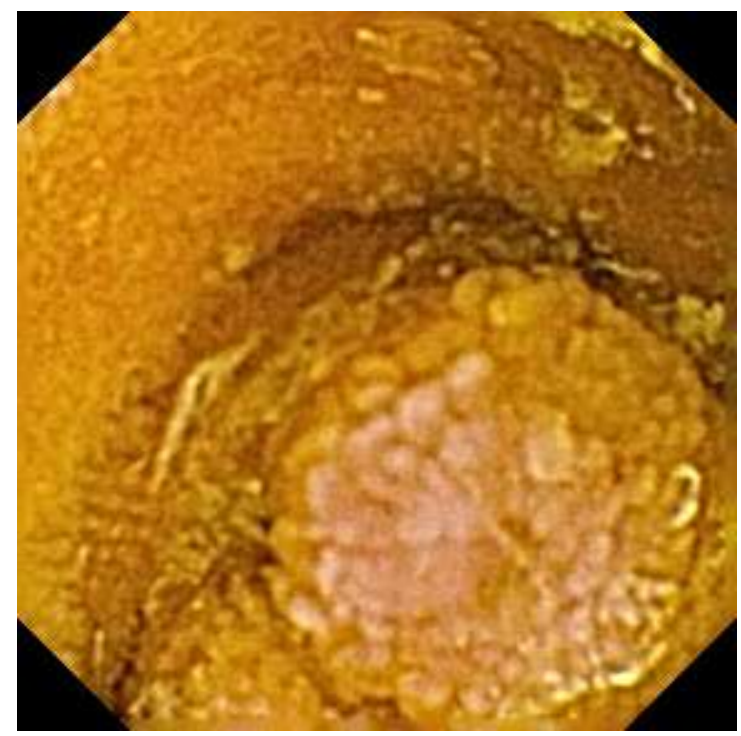

Fig. 4. Jejunal polyp at videocapsule endoscopy 
In May 2010 she was submitted on video capsule (that revealed many penducolated and sessile polyps in the distal jejunum and not in the ileum, Figure 4) and enteroscopy with single balloon (retrograde and anterograde approach) with the detection of large polyps in II-III part of duodenum (not seen by video capsule) and small polyps in distal jejunum.

In July 2010 we performed spiral enteroscopy in general anesthesia in surgical room with surgeon in stand-by for the high risk of complication. More than 15 polipectomies were done (figure 5).

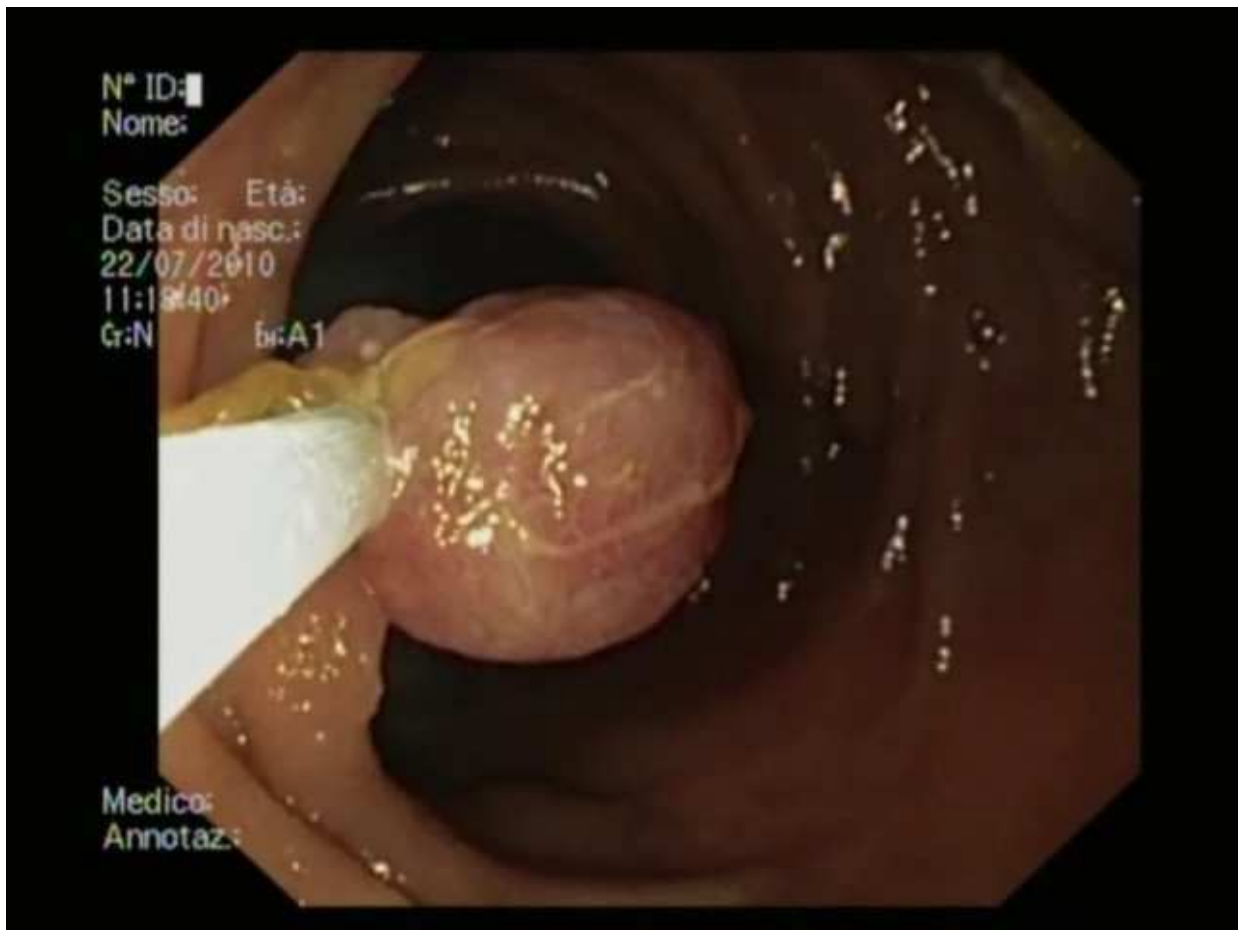

Fig. 5. Jejunal Polyp

We found small and large polyps, from $5 \mathrm{mms}$ to 5 centimeters, penduncolated and sessile, the resection was en bloc or piece meal, with taking every specimen for histological evaluation (all was amartomas).

The time of endoscopy was 4 hours . 24 hours later, we recorded an elevation of transaminases $(1.5 \mathrm{x})$ and total bilirubin $(1.3 \mathrm{x})$ without abdominal symptom ; the patient was discharged 48 hour after the procedure, with normalization of blood tests.

\subsection{Conclusion}

Because of great number of large polyps, the spiral procedure seems to be better than other assisted enteroscopy : the over tube, that fix the endoscope with a coupler during spiral advancement and permit to disengage it for conventional manipulation, allows the scope to be removed and reintroduced after every polipectomy while holding the position deep in the small bowel (Figure 6). 


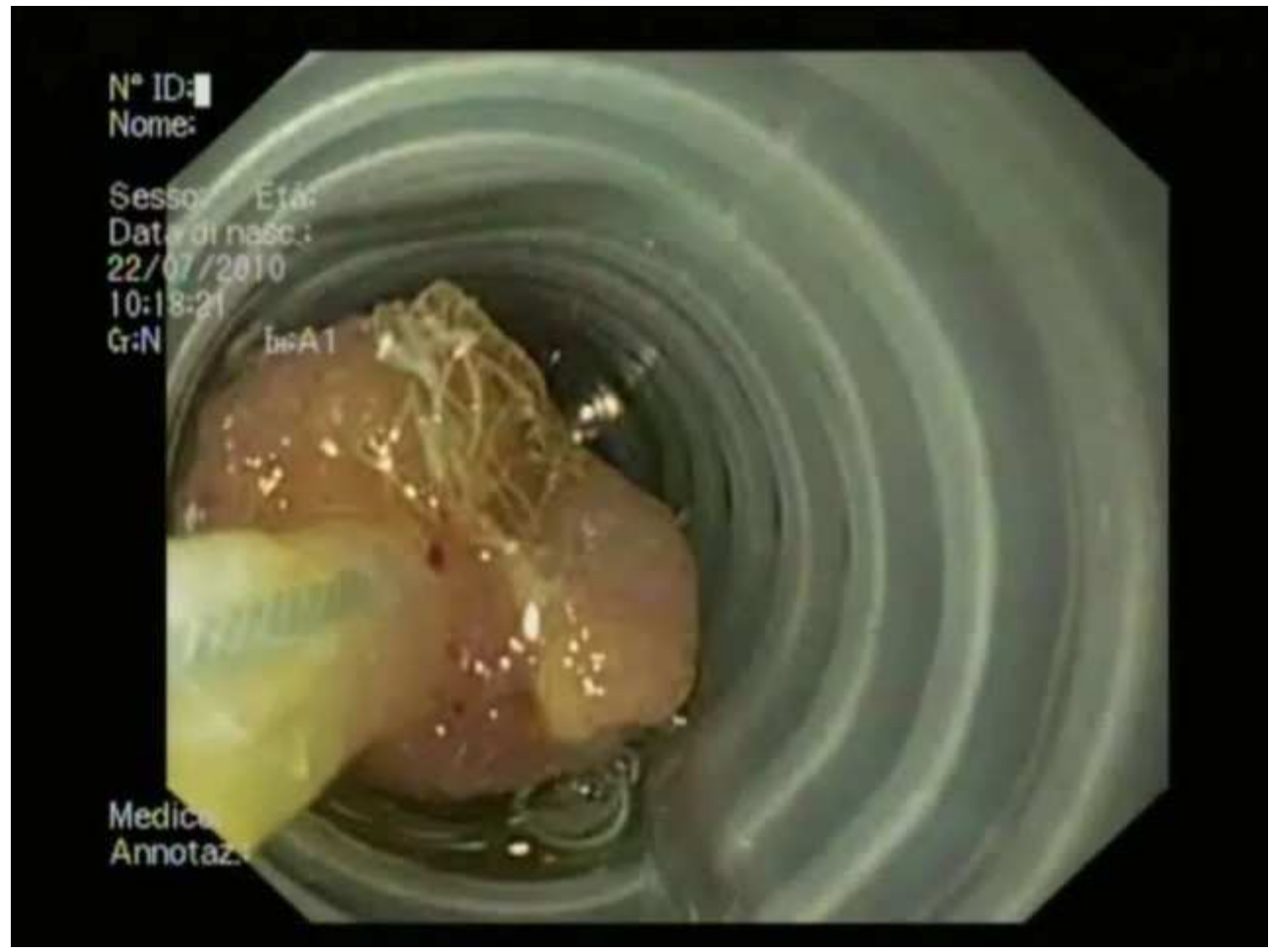

Fig. 6. Enteroscope through the overtube, polyp retrieved

Moreover, the disengagement and the rotation of the endoscope permits the best approach particularly to big polyps.

No major complications (perforation or bleeding) occurred during the procedure; the elevation of transaminases is related to transient edema in ampullary region due to trauma of the device.

\section{References}

[1] Akerman PA, Agrawal D, Cantero D, et al. Spiral enteroscopy with the new DSB overtube: a novel technique for deep peroral small-bowel intubation. Endoscopy. 2008 Dec;40(12):974-8.

[2] Morgan DR, Upchurch BR, Draganov PV, et al. Spiral enteroscopy: prospective multicenter US trial in patients with small bowel disorders. Gastrointest Endosc. 2009;69:AB127-8.

[3] Esmail S, Odstrcil EA, Mallat D, et al. A single center retrospective review of spiral enteroscopy. Gastrointest Endosc. 2009;69:AB197.

[4] Buscaglia JM, Dunbar KB, Okolo PI, 3rd, et al. The spiral enteroscopy training initiative: results of a prospective studyevaluating the Discovery SB overtube device during small bowel enteroscopy (with video). Endoscopy. 2009 Mar;41(3):194-9. 
[5] Riccioni ME, Cianci R, Spada C et al. Use of spiral enteroscopy in a tertiary endoscopy center: initial experience. Endoscopy. 2009 Sep;41(9):820.

[6] Shin EJ. Enteral stent placement using spiral enteroscopy for malignant mid-jejunal obstruction. The Dave Project 2009.

[7] Raju GS, Gerson L, Das A, et al. American Gastroenterological Association (AGA) Institute technical review on obscure gastrointestinal bleeding. Gastroenterology 2007;133:1697- 1717.

[8] Ross A, Mehdizadeh S, Tokar J, et al. Double balloon enteroscopy detects small bowel mass lesions missed by capsule endoscopy. Dig Dis Sci 2008;53:2140-2143.

[9] Rockey DC. Occult gastrointestinal bleeding. N Engl J Med 1999; 341:38-46.

[10] Hartmann D, Schmidt H, Bolz G, et al. A prospective two-center study comparing wireless capsule endoscopy with intraoperative enteroscopy in patients with obscure GI bleeding. Gastrointest Endosc 2005;61:826-832.

[11] Rondonotti E, Pennazio M, Toth E, et al. Small-bowel neoplasms in patients undergoing video capsule endoscopy: a multicenter European study. Endoscopy 2008;40:488495.

[12] Costamagna G, Shah SK, Riccioni ME, et al. A prospective trial comparing small bowel radiographs and video capsule endoscopy for suspected small bowel disease. Gastroenterology 2002;123: 999-1005.

[13] Huprich JE, Fletcher JG, Alexander JA, et al. Obscure gastrointestinal bleeding: evaluation with 64-section multiphase CT enterography- initial experience. Radiology 2008;246:562-571.

[14] Pennazio M. Small-bowel endoscopy [review]. Endoscopy 2004;36:32-41.

[15] DiSario JA, Petersen BT, Tierney WM, et al. Enteroscopes. Gastrointest Endosc. 2007 Nov;66(5):872-80.

[16] Ell C, May A. Mid-gastrointestinal bleeding: capsule endoscopy and push-and-pull enteroscopy give rise to a new medical term. Endoscopi 2006;38:73-5.

[17] Gerson LB. Double-balloon enteroscopy: the new gold standard for small-bowel imaging? Gastrointest Endosc 2005;62:71-5.

[18] Sugano KYH, Kita H. Double-balloon endoscopy: theory and practice. New YorK: Springer, 2006.

[19] Yamamoto H, Sekine Y, Sato Y, et al. Total enteroscopy with a nonsurgical steerable double-balloon method. Gastrointest Endosc 2001;53:216-220.

[20] Hartmann D, Eickhoff A, Tamm R, et al. Balloon-assisted enteroscopy using a singleballoon technique. Endoscopy 2007; 39(Suppl 1):E276.

[21] Akerman PA, Cantero D. Spiral enteroscopy and push enteroscopy. Gastrointest Endosc Clin N Am. 2009 Jul;19(3):357- 69.

[22] Luis F. Lara, Shailender Singh, Jayaprakash Sreenarasimhaiah. Initial experience with retrograde overtube-assisted enteroscopy using a spiral tip overtube. Proc (Bayl Univ Med Cent) 2010;23(2):130-133.

[23] Buscaglia JM, Dunbar KB, Okolo PI, et al. The spiral enteroscopy training initiative: results of a prospective study evaluating the discovery SB overtube device during small bowel enteroscopy. Endoscopy. 2009;41:194-199.

[24] Mantas A, Masand A, DeMarco D. A single center retrospectivecomparison of double balloon and spiral enteroscopy. Am JGastroenterol. 2009;104(Suppl 3):S508. 
[25] Aldler A, Eckardt E, Veltzke-Schlieker W, Papnikolau I, Giannakoulopoulou E, Wiedemann B, Rosch T. Is Spirale Enteroscopy superior to double ballon enteroscopy in diagnosing the small intestine? First resul of a large prospective randomized comparative study. Presented at DGBE-BV 2010 (German society for endoscopy and imaging)

[26] May A, Farber M, Aschmoneit I, et al. Prospective multicenter trial comparing pushand-pull enteroscopy with the single- and double-balloon techniques in patients with small-bowel disorders. Am J Gastroenterol2010; 105:582-4.

[27] Frieling T, Heise J, Sassenrath W, Hulsdok A, Kreysel C. Prospective comparison between doble-balloon enteroscopy and spiral enteroscopy. Endoscopy. 2010;42: 8858

[28] Khashab MA, Lennon AM, Dunbar KB, Singh VK, Chandrasekhara V, Giday S, et al. A comparative evaluation of singleballoon enteroscopy and spiral enteroscopy for patients with midgut disorders. Gastrointest Endosc. 2010;72:766-72.

[29] Anne Marie Lennon, MD, PhD, Vinay Chandrasekhara, MD, Eun Ji Shin, MD, Patrick I. Okolo,III, MD, MPH Spiral-enteroscopy-assisted enteral stent placement for palliation of malignant small-bowel obstruction (with video) Gastrointestinal Endoscopy Volume 71, No. $2: 2010$

[30] Aabakken L, Bretthauer M, Line PD. Double-balloon enteroscopy for endoscopic retrograde cholangiography in patients with a Roux-en-Y anastomosis. Endoscopy. 2007;39:1068-71.

[31] Chandrasekhara V, Lennon AM, Singh V, Liang D, Okolo P. ERCP using spiral enteroscopy in patients with altered gastrointestinal anatomy. Am J Gastroenterol. 2009;104(Suppl 3):S384

[32] Shah RJ. Spiral enteroscopy-assisted ERCP in patients with longlimb surgical biliary bypass. Endoscopy. 2009;41(Suppl 1):A25.

[33] Sanjay RH, Sharon D, Kevan I, Stephen JH, Jeffrey LT, Oleh H. Overtube-assisted ERCP in patients with surgically altered anatomy: a single center one-year experience. Gastrointest Endosc. 2009;69:AB193. 


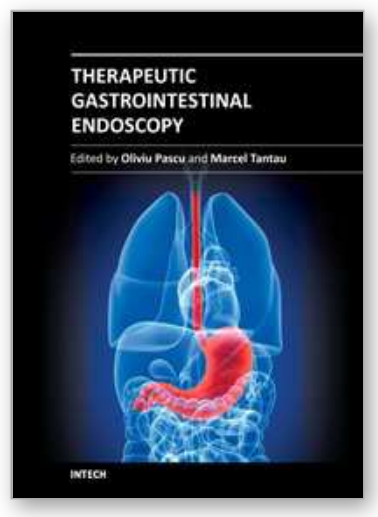

\author{
Therapeutic Gastrointestinal Endoscopy \\ Edited by Prof. Oliviu Pascu
}

ISBN 978-953-307-743-7

Hard cover, 216 pages

Publisher InTech

Published online 22, September, 2011

Published in print edition September, 2011

Endoscopy has had a big role in the development of modern gastroenterology. Modern endoscopy will certainly be more therapeutic. It started with endoscopic hemostasis and polipectomy, than beginning of the 1970 's with the advent of endoscopic sphincterotomy extended to biliopancreatic pathology and has a huge impact in this difficult pathology. Plastic stents made the first steps in endoscopic palliation of neoplastic jaundice, metallic stents, covered or uncovered are better for biliary palliation and can be used also for palliation neoplastic obstruction at different levels of the digestive tube. Resection of digestive tumors has evolved now to sub-mucosal resection, looking to have one-piece complete resection. Interventional endoscopy is now very complex and takes a lot of time for endoscopists to learn properly these techniques. This book is a very good up-to-date overview of new techniques of interventional endoscopy for those who want to learn or develop their knowledges in this field.

\title{
How to reference
}

In order to correctly reference this scholarly work, feel free to copy and paste the following:

Marco Balzarini, Marco Orsello and Mario Del Piano (2011). Therapeutic Uses of Spiral Enteroscopy, Therapeutic Gastrointestinal Endoscopy, Prof. Oliviu Pascu (Ed.), ISBN: 978-953-307-743-7, InTech, Available from: http://www.intechopen.com/books/therapeutic-gastrointestinal-endoscopy/therapeutic-uses-of-spiralenteroscopy 1

\section{INTECH}

open science | open minds

\section{InTech Europe}

University Campus STeP Ri

Slavka Krautzeka 83/A

51000 Rijeka, Croatia

Phone: +385 (51) 770447

Fax: +385 (51) 686166

www.intechopen.com

\section{InTech China}

Unit 405, Office Block, Hotel Equatorial Shanghai

No.65, Yan An Road (West), Shanghai, 200040, China 中国上海市延安西路65号上海国际贵都大饭店办公楼 405 单元

Phone: +86-21-62489820

Fax: $+86-21-62489821$ 
(C) 2011 The Author(s). Licensee IntechOpen. This chapter is distributed under the terms of the Creative Commons Attribution-NonCommercialShareAlike-3.0 License, which permits use, distribution and reproduction for non-commercial purposes, provided the original is properly cited and derivative works building on this content are distributed under the same license. 